Florida International University

FIU Digital Commons

FIU Electronic Theses and Dissertations

University Graduate School

$4-17-2020$

\title{
Mind Wandering as a Mechanism of Attentional Dysfunction among Children with ADHD
}

Brittany Merrill

Florida International University, bmerr012@fiu.edu

Follow this and additional works at: https://digitalcommons.fiu.edu/etd

Part of the Clinical Psychology Commons

\section{Recommended Citation}

Merrill, Brittany, "Mind Wandering as a Mechanism of Attentional Dysfunction among Children with ADHD" (2020). FIU Electronic Theses and Dissertations. 4529.

https://digitalcommons.fiu.edu/etd/4529

This work is brought to you for free and open access by the University Graduate School at FIU Digital Commons. It has been accepted for inclusion in FIU Electronic Theses and Dissertations by an authorized administrator of FIU Digital Commons. For more information, please contact dcc@fiu.edu. 


\section{FLORIDA INTERNATIONAL UNIVERSITY}

Miami, Florida

MIND WANDERING AS A MECHANISM OF ATTENTIONAL DYSFUNCTION AMONG CHILDREN WITH ATTENTION DEFICIT HYPERACTIVITY DISORDER

A dissertation submitted in partial fulfillment of the requirements for the degree of

DOCTOR OF PHILOSOPHY

in

PSYCHOLOGY

by

Brittany Merrill 
To: Dean Michael R. Heithaus

College of Arts, Sciences, and Education

This dissertation, written by Brittany M. Merrill, and entitled Mind Wandering as a Mechanism of Attentional Dysfunction Among Children with Attention Deficit Hyperactivity Disorder, having been approved in respect to style and intellectual content, is referred to you for judgment.

We have read this dissertation and recommend that it be approved.

$\begin{array}{r}\hline \text { Joseph S. Raiker } \\ \hline \text { Aaron T. Mattfeld } \\ \hline \text { Melissa Baralt } \\ \hline \text { William E. Pelham Jr., Major Professor }\end{array}$

Date of Defense: April 17, 2020

The dissertation of Brittany Merrill is approved.

Dean Michael R. Heithaus
College of Arts, Science, and Education

College of Arts, Science, and Education

Andrés G. Gil

Vice President for Research and Economic Development and Dean of the University Graduate School

Florida International University, 2020 


\section{ACKNOWLEDGMENTS}

I would like to acknowledge Joseph Raiker and Aaron Mattfeld for their continued support with this dissertation from the very beginning. I would like to thank Jaclyn Schwartz and Melissa Baralt for serving on my dissertation committee and providing valuable feedback. The ADHD lab at FIU, including Fiona Macphee, Marcela Ramos, Amy Altszuler, and Xin Zhao, were integral in the design and implementation of this project. Most importantly, I would like to thank my mentor and dissertation chair, William Pelham, for his guidance for the better part of the last decade. I have learned a great deal regarding scientific methods, mental health, and psychosocial treatment. The idea and implementation of this dissertation would not have been possible without his mentorship. This dissertation was funded in part by the Center for Children and Families Dissertation Grant and Graduate Student Dissertation Seed Funds from the Department of

Psychology at FIU. This study took place as part of a larger grant funded by the National Institute of Mental Health (R01 MH099030). 


\begin{abstract}
OF THE DISSERTATION
MIND WANDERING AS A MECHANISM OF ATTENTIONAL DYSFUNCTION AMONG CHILDREN WITH ATTENTION DEFICIT HYPERACTIVITY DISORDER
\end{abstract}

\author{
by
}

Brittany Merrill

Florida International University, 2020

Miami, Florida

\title{
Professor William E. Pelham Jr., Major Professor
}

The current study aims to experimentally investigate the occurrence of mind wandering (MW) among children with Attention-Deficit Hyperactivity Disorder (ADHD).

Participants included 59 children with ADHD and 55 typically developing children. Participants completed a sustained attention task that included non-target photos of people to which children were told to respond and target photos of animals-e.g., birds, bears, cows - that children were instructed to withhold response to. Non-target photos included photos of children doing activities such as sports and birthday parties, a portion of which were the participant's own photos (self-referential [SR] photos) in order to experimentally increase SR internal distraction or MW defined as increases in reaction time variability (RTV) following SR stimuli. The ADHD group also participated in a classroom study with two MW conditions (free play or movie before and after class work) and a cross-over methylphenidate (MPH) trial. MW conditions were hypothesized to lead to impaired classroom productivity via internal distraction. On the attention task, there was a significant main effect of ADHD diagnostic status and SR stimuli indicating that both ADHD diagnostic status and SR stimuli were associated with increased RTV. A 
marginally significant interaction effect between ADHD status and SR stimuli indicated that SR stimuli resulted in significantly higher RTV among children with ADHD and not among children without ADHD. Within the ADHD group, MPH led to decreased RTV. In the classroom setting, MW conditions were associated with lower productivity and MPH led to higher productivity. The current study utilized novel methods to manipulate and measure MW and is the first to assess MW among children with ADHD without relying on self-report. Results provide evidence that children with ADHD are more susceptible to MW than their peers and that MW may underlie the variability in performance on cognitive and academic tasks often noted among children with ADHD. 


\section{TABLE OF CONTENTS}

CHAPTER

PAGE

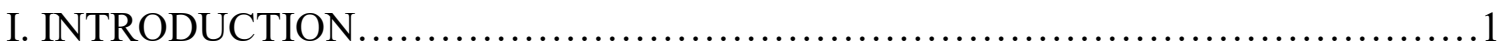

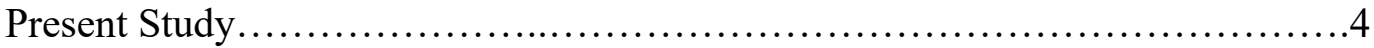

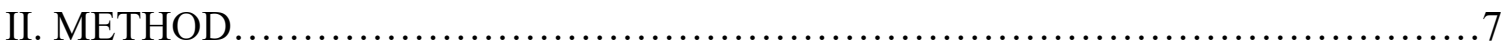

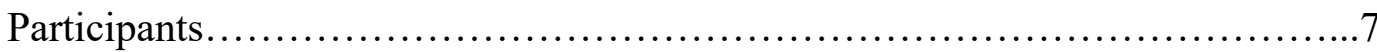

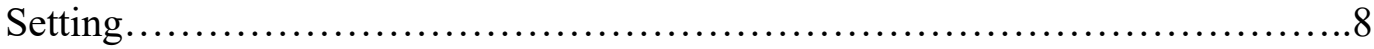

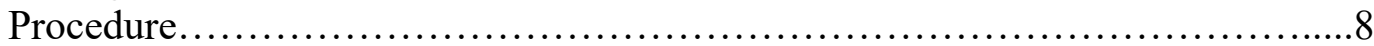

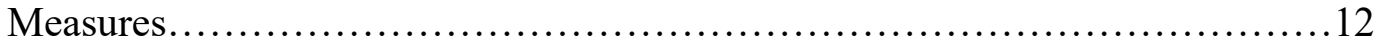

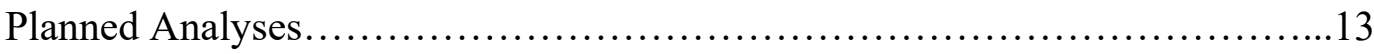

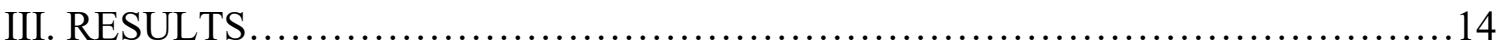

Sustained Attention to Response Task .................................. 14

Classroom Study................................................................ 15

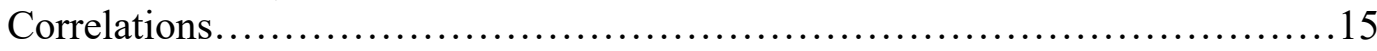

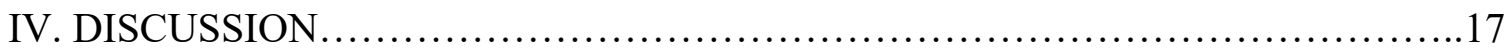

Mind Wandering on the Sustained Attention to Response Task..................18

Mind Wandering in the Classroom Study ................................... 19

Medication Effects Across Settings.......................................20

Limitations and Future Directions.......................................... 21

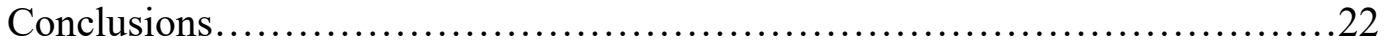

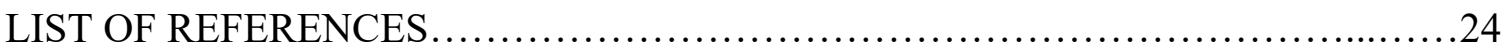

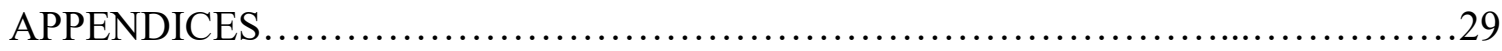

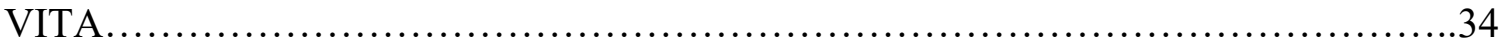




\section{LIST OF TABLES}

TABLE

PAGE

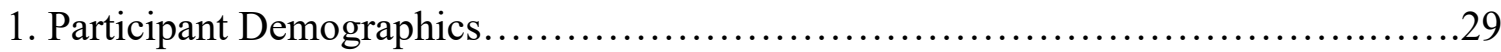

2. Sustained Attention to Response Task (SART) Performance .................................30

3. Seatwork Completion Among Children with ADHD...................................31

4. Correlations Between Reaction Time Variability and Seatwork Completion.............32 


\section{ABBREVIATIONS AND ACRONYMS}

\begin{tabular}{|c|c|}
\hline ADHD & Attention-Deficit Hyperactivity Disorder \\
\hline CBCL & Child Behavior Checklist \\
\hline DBD & Disruptive Behavior Disorder \\
\hline $\mathrm{DMN}$ & Default Mode Network \\
\hline DSM & Diagnostic Statistical Manual of Mental Disorders \\
\hline IQ & Intelligence Quotient \\
\hline MPH & Methylphenidate \\
\hline MW & Mind Wandering \\
\hline $\mathrm{NIMH}$ & National Institute of Mental Health \\
\hline NR & Non-self-referential \\
\hline PERMP & Permanent Product \\
\hline RT & Reaction Time \\
\hline RTV & Reaction Time Variability \\
\hline SART & Sustained Attention to Response Task \\
\hline SR & Self-referential \\
\hline STP & Summer Treatment Program \\
\hline TA & Target \\
\hline
\end{tabular}




\section{CHAPTER I}

\section{INTRODUCTION}

Childhood Attention Deficit Hyperactivity Disorder (ADHD) is a critical public health concern given the high prevalence rate $(10 \%$; Centers for Disease Control and Prevention, 2011), significant societal and familial costs (Pelham, Foster, \& Robb, 2007;

Robb et al., 2011), and poor long-term outcomes across domains of functioning (Barkley, Murphy, \& Fisher, 2010; Merrill et al., 2019). Children with ADHD present with developmentally inappropriate hyperactivity and impulsivity and significant attention deficits leading to a variety of cross-situational impairments in peer relationships, academic functioning, and family functioning (Nigg \& Barkley, 2014). However, mechanisms of the attention deficit have been difficult to specify via translation to cognitive tasks. For example, despite the widespread belief that children with ADHD are distracted by external stimuli (e.g., sights and sounds in the classroom), research indicates that children with ADHD are not uniquely susceptible to distractors in their environment or on cognitive tasks (for review, see Huang-Pollock, Nigg, \& Carr, 2005) except in a single study that reported heightened distractibility when an engaging movie (but not rock music) was playing during class time (Pelham et al., 2011). Thus, we are left with the notion that children with ADHD are more inattentive in classroom and laboratory settings, but that inattention does not appear to be caused by external distractors. This raises the question of whether an alternative mechanism of internal distraction or mind wandering (MW) causes what parents and teachers ubiquitously report as high distractibility and inattentive behaviors that interfere with functioning in ADHD. 
Indeed, adults with elevated ADHD symptoms, compared to those with lower ADHD symptoms, are more likely to engage in periods of MW that interfere with their ongoing task performance despite not gaining self-perceived benefit from their MW (Franklin et al., 2014). Spontaneous MW, specifically, has been found to relate to adult ADHD symptoms in clinical and non-clinical samples (Seli, Smallwood, Cheyne, \& Smilek, 2015). Further, MW has been shown to contribute to impairment beyond ADHD symptoms among adults (Mowlem et al., 2016). Importantly, these studies focused on adults with ADHD symptoms or diagnoses, though the literature is clear that individuals first diagnosed with ADHD in adulthood are distinct from those diagnosed in childhood then followed prospectively into adulthood (Barkley, Murphy, \& Fischer, 2010).

Further, indirect measures of MW markedly overlap with ADHD-related cognitive deficits and symptoms, providing additional evidence that MW may play a critical role in attentional deficits observed in this population. For instance, high reaction time variability (RTV) is often observed in individuals with ADHD on cognitive tasks, and RTV has also been used as an indirect measure of internal distraction given its high correlation with probe-caught MW (Epstein et al., 2011; Kofler et al., 2013; Mrazek, Smallwood, \& Schooler, 2012; Smallwood, Beach, Schooler, \& Handy, 2008; Tamm et al., 2012). MW is related to a variety of deficits that are implicated in ADHD such as sustained attention (Cheyne, Solman, Carriere, \& Smilek, 2009), excessive motor movements (Seli et al., 2014), and poor educational performance (Smallwood, Fishman, \& Schooler, 2007). Critically, these same symptoms — sustained attention, hyperactivity, off-task behavior-improve when children receive stimulant medication (Carlson et al., 1992; Greenhill et al., 2001; Pelham et al., 1993; Pelham et al., 1995; Pelham et al., 2001; 
Pliszka, 2007; Swanson et al., 1993). If MW is a core component of attentional problems among children with ADHD, it is critical to assess the effects of stimulant medication on MW.

Altogether, children with ADHD are not distracted by their environment, they present with symptoms and attentional deficits that mirror those associated with MW, and adults with ADHD report heightened MW. It is therefore critical to systematically assess MW among children with ADHD. A major barrier to researching MW during childhood, though, is children's limited ability to report their own mental activity. Children with ADHD have particularly poor insight and invalid self-perceptions (Hoza et al., 2004; Owens, Goldfine, Evangelista, Hoza, \& Kaiser, 2007), and much of the extant MW research utilizes probe-caught and self-reported MW as the outcome variable which cannot be used validly among children with ADHD. The only study to date examining MW among children with ADHD utilized self-reported thought content during attentional lapses in a go/no-go task (Van den Driessche et al., 2017). Given that children were asked to report what they were thinking, it is not surprising that unmedicated children with ADHD reported that their minds were "blank" as opposed to reporting their thought content. Importantly, though, medicated children with ADHD were more likely than controls to report MW, providing preliminary support for the MW hypothesis.

Fortunately, compelling systems neuroscience research related to the default mode network (DMN) not only provides further support for the MW hypothesis of ADHD dysfunction but also insight into potentially effective experimental manipulations to increase and measure changes in MW. The DMN is characterized by spontaneous correlations of neural activity during rest, suppression of activation during externally 
goal-directed tasks, and activation during retrospective and prospective self-referential (SR) tasks (Andrews-Hanna, Reidler, Sepulcre, Poulin, \& Buckner, 2010; Buckner, Andrews-Hanna, \& Schacter, 2008; Christoff, Gordon, Smallwood, Smith, \& Schooler, 2009). The DMN and neural networks related to task performance are typically anticorrelated — when the DMN is active, task positive networks are less active and vice versa-, and this anticorrelation facilitates the individual's ability to focus or sustain attention on a given external activity (Buckner et al., 2008; Weissman, Roberts, Visscher, \& Woldorff, 2006). Among individuals with heightened ADHD symptoms, however, DMN hyperactivation interferes with task positive network activity (i.e., the networks are not anticorrelated; Cortese et al., 2012), and DMN hyperactivation correlates with RTV among children with ADHD (Querne et al., 2014). Given its defined function, DMN intrusion or hyperactivation could represent internally-generated thought interference with the ongoing, external task and therefore affect sustained attention. DMN research suggests, therefore, that MW among individuals with ADHD is likely self-referential in nature. Based on this inference, the current study aims to increase and measure MW among children with ADHD by manipulating the presence of self-referential distractors during naturalistic and computer tasks.

\section{Present Study}

It is clear that novel methods to evaluate MW among children need to be devised, and the current study aimed to address this gap in the literature by developing a novel sustained attention to response task (SART) integrating self-referential (SR) stimuli, which has been used to elicit DMN activity (Buckner et al., 2008) and is thought to be the primary content of internal distraction and $\mathrm{MW}$, to evaluate differences in MW 
susceptibility among children with and without ADHD. Participants included 55 children with ADHD and 55 children without ADHD who completed the novel, MW SART one to two times each. Children with ADHD completed the task once when receiving placebo and once when receiving their lowest effective dose of Concerta MPH. Performance in the ADHD group on placebo was compared to performance in the control group. We hypothesized that RTV would be greater following SR stimuli-photos of themselves at parties, sports events, etc.—compared to non-self-referential (NR) stimuli—photos of other children/families — and that the increase would be significantly greater in the ADHD group compared to the control group. Based on previous research, we did not expect ADHD to predict longer average reaction time, rather that ADHD status would relate to significantly greater RTV. Relatedly, we hypothesized that medication would lead to decreased RTV and would not significantly impact average RT. Currently, there is insufficient evidence to hypothesize whether stimulant medication will ameliorate a MWrelated increase in RTV.

A parallel second study took place with the ADHD group, $n=59$, within an analogue elementary classroom as part of an intensive summer day treatment program. MW was manipulated in the classroom setting by introducing a salient stimulus - free play with toys and tablets or an engaging movie - prior to and after 30 minutes of seatwork completion in order to increase the probability that children would be thinking about something other than their own work. Children were able to choose what to play with each day in the free play condition, and they watched engaging excerpts from popular children's movies on movie days. Seatwork completion on these days was compared to seatwork completion on days in which children watched an ostensibly non- 
engaging newscast. After the distractors (i.e., free play toys or movie) were removed from the environment, detrimental impact on seatwork productivity is interpreted as an increase in internal distraction or MW during the task at hand. Children with ADHD also participated in a cross-over stimulant medication trial in which they received their lowest effective dose of Concerta for three weeks and crossed-over to placebo for the following three weeks or vice versa. We hypothesized that children would complete less work in both the MW conditions - free play and fun movie — compared to the control condition. Such findings would indicate that children were distracted after the external stimuli was no longer present, implicating internal distraction or mind wandering. We also hypothesize that stimulant medication would lead to improved seatwork productivity based on decades of research documenting the salutary effects of stimulants on productivity (Carlson et al., 1992; Pelham et al., 1993; Pelham et al., 1995; Pelham et al., 2001; Pliszka, 2007). We will also examine correlations between performance on the MW SART and seatwork productivity. We hypothesize that RTV on the MW SART will be moderately correlated with measures of seatwork productivity. 


\section{CHAPTER II}

\section{METHOD}

\section{Participants}

Fifty-nine children with ADHD and 55 matched control participants (ages 7-12 years) participated in the study. Inclusion criteria included a Full Scale IQ above 70. ADHD diagnosis was established based on the DSM-5 (American Psychiatric Association, 2013) utilizing a combination of parent and teacher rating scales (i.e., Disruptive Behavior Disorders rating scale [DBD]; Masetti et al., 2003) and semistructured clinical interview (Pelham, Fabiano, \& Massetti, 2005). Children with ADHD were recruited from the Summer Treatment Program (STP) as part of a larger NIMHfunded trial (R01-MH099030). Exclusion criteria for the ADHD group included currently or in the past 6 months receiving psychotropic medication for conditions other than ADHD, medical or psychiatric conditions that could be worsened by stimulants (seizures, pregnancy, mania, etc.,), a documented intolerance or lack of response to methylphenidate, or a severe comorbid disorder requiring emergent treatment not offered as part of the study (e.g., youth with active suicidal ideation). Typically developing controls were recruited from area public schools and the community via flyers and were excluded if they had T-score $>60$ on any externalizing subscale on the Child Behavior Checklist (CBCL; Achenbach \& Rescorla, 2001). Youth who had a diagnosis of Autism Spectrum Disorder of moderate or high severity (i.e., requiring substantial or very substantial supports) were excluded from either group. Participants were mostly boys (80\%), 85.2\% white, and 86\% Hispanic. Among the children with ADHD, $62.7 \%$ met 
criteria for Oppositional Defiant Disorder and 5.1\% met criteria for Conduct Disorder (see Table 1 for demographic information).

\section{Setting}

Children with ADHD participated in the Summer Treatment Program (STP), an intensive, evidence-based treatment program for childhood ADHD (for description, see Pelham et al., 2010) which lasted from 8AM-5PM for 8 weeks. Throughout the STP, a response-cost system and other behavioral contingencies were in place. Children were taken to a private classroom at the STP, which took place at a local middle school, to complete the SART task with the examiner. Children without ADHD completed the tasks and other study procedures in a private room at the university where this study took place or in a private office/conference room in their home elementary school. Children without ADHD largely completed tasks during the academic year due to recruitment through the elementary schools.

During the STP, children with ADHD were also in a one-hour long analogue classroom setting twice per day, and they completed grade-level appropriate seatwork in the morning classroom during which the second study took place. The response-cost procedure in the morning classroom included point losses for breaking rules related to behavior (e.g., be respectful of others), but did not include point losses related to seatwork productivity (e.g., stay on task).

\section{Procedure}

Parents of children in both groups signed consent forms and completed the Child Behavior Checklist (CBCL; Achenbach \& Rescorla, 2001) to screen for emotional and behavioral problems. Children who were 8 years of age or older signed assent 
documentation. The Wechsler Abbreviated Scale of Intelligence, second edition, (WASIII; Wechsler, 2011) was administered along with the numerical operations, word reading, and spelling subscales of the Wechsler Individual Achievement Test, third edition, (WIAT-II; Wechsler, 2009) in both groups. All procedures completed in this study were approved by the Florida International University Institutional Review Board. Parents in the control group were provided $\$ 20$ for their time.

Medication Procedures. During the first two weeks of the STP, children with ADHD underwent a double-blind, placebo-controlled evaluation of three doses of longacting methylphenidate (MPH; $18 \mathrm{mg}, 27 \mathrm{mg}$, or $36 \mathrm{mg}$ ). Each child's lowest effective dose was determined, and then children were randomized to either receive placebo or MPH for the next three weeks and crossed-over to the other condition for the last three weeks of the STP. Children with ADHD completed the MW sustained attention to response (SART) task (described below) once when they were receiving MPH and once on placebo during the STP.

Participant Matching. Control children were matched on gender and closely on age with a child with ADHD, and, as their task performance was compared with the ADHD child's performance on placebo, control children completed the task 1-2 times depending on when the matched child with ADHD received placebo to control for practice effects. Put another way, if a child without ADHD was matched with a child with ADHD who received placebo in the second cross-over phase, the matched child without ADHD completed the task twice, and the second task administration was used herein. 
Mind Wandering Sustained Attention Task. The SART in the current study was comprised of non-targets (pictures to which children were instructed to provide a response as quickly as possible) and targets (TA; pictures of animals— - e.g., birds, bearsto which children were instructed to withhold a response). Real life images were used for all the pictures in this task. Each picture was presented for $2000 \mathrm{~ms}$ followed by a fixation cross for $500 \mathrm{~ms}$ between stimuli. To evaluate the extent to which self-referential internal distraction, i.e., MW, impacts task performance, two non-target stimuli types were presented throughout the task: 1) photos provided by the participant's family (selfreferential [SR] trials) and 2) photos of people unknown to the child (non-self-referential [NR] trials). The task was comprised of $8 \%$ SR trials, $84 \%$ NR trials, and $8 \%$ TA trials. The large proportion of non-target trials was needed to ensure that pressing the button dominated as the prepotent response. The task contained three types of blocks comprised of NR, SR, and TA trials in the following orders within each block: 1) NR Block- NR NR NR NR, 2) SR Block- SR NR NR NR, and 3) Target Block- NR NR NR TA. Each block was repeated 29 times each throughout the task. We hypothesized that reaction time variability (RTV) would increase after SR stimuli presentation. In other words, RTV in the three NR trials in SR Blocks would be greater than RTV in the latter three NR trials in NR Blocks. Greater RTV during SR blocks compared to NR blocks would therefore indicate heighted internal distraction or MW following the presentation of self-referential stimuli (i.e., photos of the participant/participant's family), and MW is operationally defined as significantly worse attentional performance related to SR - participant's own photos-stimuli presentation. 
Classroom Mind Wandering Manipulations. The second study included only children with ADHD and involved manipulating the classroom environment in the STP in order to increase MW and negatively impact classroom productivity. Classroom manipulations took place in the morning classroom during the STP. To manipulate the frequency of MW among children with ADHD, there were three conditions for the first 5 minutes and the last 10 minutes of the morning classroom at the STP randomly distributed over days: 1) a SR condition where the children had free play with favorite toys and tablets, 2) an engaging stimuli condition where children watched an excerpt from a favorite movie that they voted for (e.g., Minions), or 3) a control condition where children watched a non-engaging TV excerpt (e.g., CSPAN). At the beginning of each class, children were explicitly told that the same condition would be present at the end of class. In other words, teachers told children they would have 10 minutes at the end of the class to continue playing with toys, watching the movie, or watching CSPAN based on the condition for that day. For the middle 30 minutes of class time, children completed grade-level appropriate math, reading, and language arts work (10 minutes per subject).

In the free play condition, a bin of toys and enough tablets for each child to have one were brought into the room. Children were asked during assent what types of games they like to play, and games requested, such as ROBLOX, Minecraft, Sonic, Angry Birds, and others, were downloaded on the tablets. Toys available included Legos, coloring books and crayons, cars, Shopkins, and others. For the movie condition, children watched movies they had suggested and then voted for (e.g., Minions, Up, The Lego Movie, and others). Children watched excerpts from different movies each day, and excerpts were pre-selected from 'exciting' portions of the movie to ensure consistency 
across classrooms and avoid having children only watch opening credits/scenes that would likely not be as engaging. Archived CSPAN videos of congress were selected and screened by staff to ensure that there was no child-inappropriate content. CSPAN was chosen as the control condition to reduce the likelihood that children would think about that task while completing seatwork. Children were explicitly told that they would have free play, movie, or CSPAN after seatwork regardless of how much work they completed. In other words, these activities were not contingent on productivity. Across the MW and control conditions, there were no differences in the environment during classwork completion (i.e., the toys were removed from view and the media projector was turned off).

Similar manipulations of the classroom environment have been implemented in numerous studies over decades. Manipulations of external distractors (Pelham et al., 2011), small-group instruction (Hart et al., 2011), extended time (Pariseau et al., 2010), sugar ingestion (Milich \& Pelham, 1986), behavioral treatment (Fabiano et al., 2007), stimulant medication (Pelham et al., 2001), and combined treatment (Pelham et al., 1993; Fabiano et al., 2007) have all been implemented effectively in the STP setting. The current study utilizes similar methods due to the long history of research evidence indicating its methodological rigor.

Measures

MW Task Performance. Criteria include reaction time (RT) and RTV (standard deviation of reaction time) calculated from the 3 NR trials that followed either the NR (NR Block) or SR (SR Block) stimuli presentation, respectively. Incorrect responses and RTs below 200 ms were excluded from analyses. 
Seatwork Completion. Using procedures documented as effective in multiple studies of medication effects in the STP classroom (see above, e.g., Fabiano et al., 2007; Pelham et al., 2011), children completed grade-level appropriate seatwork in math (Permanent Product [PERMP]), reading, and language arts and were assigned more work than they were able to complete within the 30 minute class time to allow for effects of the manipulations. The number of problems completed served as the dependent measure. Planned Analyses

Generalized linear mixed models (i.e., PROC GLIMMIX in SAS 9.4) were used to evaluate between- (Group: ADHD vs. control) and within-subject (Block type: NR block vs. SR block) effects on RT and RTV. Identical procedures were used to examine the effect of MPH (Placebo vs. MPH), block type (NR block vs. SR block), and their interaction within the ADHD group.

To analyze whether the MW conditions and MPH affected classroom productivity, a generalized mixed model fit to a Poisson distribution (as the criterion is a count variable: number of problems completed) was used to account for the repeated measurement over days. Analyses controlled for the child's medication crossover order (i.e., medication or placebo first), the child's assigned classroom (which methodologically controls for both child age and classroom teacher), their interaction, and interactions between these variables and MPH and MW condition, respectively. The relation between performance on the SART and classroom productivity was evaluated via correlation. 


\section{CHAPTER III}

\section{RESULTS}

\section{Sustained Attention to Response Task}

Unmedicated children with ADHD were compared to typically developing controls on SART measures (Table 2). ADHD status did not significantly predict average RT, $F(1,120)=1.02, p=.31$. Block type was a significant predictor of average RT, $F(1,120)=36.80, p<.001$, such that RT was slower on average following SR stimuli

relative to NR stimuli. The interaction between ADHD status and block type on average RT was not significant, $F(1,120)=.640, p=.42$.

ADHD status significantly predicted RTV $F(1,120)=22.05, p<.001$, such that children with ADHD had higher RTV than children without ADHD. Block type (SR vs. $\mathrm{NR}$ ) significantly predicted RTV, $F(1,120)=6.67, p=.01$, such that RTV was higher following the presentation of SR stimuli relative to NR stimuli. The interaction between ADHD and block type was marginally significant, $F(1,120)=3.82, p=.053$ (Figure 1 ). Specifically, in the control group, SR stimuli was not significantly related to higher RTV, $\mathrm{t}=-.52, p=.61$. However, in the ADHD group, SR stimuli was related to increased RTV, $\mathrm{t}=-2.86, p=.005$

Next, within-subject analyses evaluating the effects of block type and medication were conducted within the ADHD group only (see Table 2 for means). Block type (SR block vs. NR block) significantly predicted average RT, $F(1,54)=21.52, p<.001$, such that average RT increased about $20 \mathrm{~ms}$ in the SR blocks compared to NR blocks. Medication status and the interaction between medication status and block type were not 
significant predictors of average RT, $F(1,52)=1.75, p=.19, F(1,52)=.19, p=.67$, respectively.

Block type significantly predicted RTV, $F(1,54)=8.95, p=.004$, such that RTV was higher in SR blocks compared to NR blocks. Further, medication significantly predicted RTV, $F(1,52)=14.34, p<.001$, such that RTV was reduced by approximately $10 \mathrm{~ms}$ when children received medication. The interaction between block type and medication was not significant, $F(1,52)=.26, p=.62$.

\section{Classroom Study}

In the analog classroom setting, the impact of MW manipulations and MPH on performance was examined in the ADHD group (Table 3). There were significant main effects of MW condition and MPH on seatwork completion, $F(2,112)=11.49, p<.001$, $F(2,112)=1943.28, p<.001$, respectively. The interaction between MW condition and MPH was also significant, $F(2,112)=4.35, p=.02$. As shown in Table 3 , when receiving placebo, children's seatwork completion was lower in the Free Play MW condition compared to both the control condition and the Movie condition, $\mathrm{t}=3.71, p<$ $.001, \mathrm{t}=4.00, p<.001$, respectively, which were not significantly different from each other, $\mathrm{t}=0.24, p=.81$. Conversely, when receiving stimulant medication, children completed less work in both MW conditions (Free Play, $\mathrm{t}=2.90, p=.005$, and Movie, $\mathrm{t}=$ $2.63, p=.01)$ compared to the control condition. MPH led to increased classroom productivity across MW conditions, $p \mathrm{~s}<.001$.

\section{Correlations}

For the ADHD group only, correlations between seatwork completion and MW task performance across MW conditions and medication conditions are displayed in 
Table 4. Average RT did not correlate with seatwork completion in any conditions- $-\mathrm{MW}$ conditions or medication conditions, $p \mathrm{~s}>.10$. In the placebo condition, NR block RTV was marginally significantly correlated with seatwork completion for both the MW control and Free Play conditions, $\mathrm{r}=-.241, p=.079 ; \mathrm{r}=-.230, p=.095$, respectively. In the medication condition, NR block RTV was marginally significantly associated with seatwork completion across conditions, MW control, $\mathrm{r}=-.233, p=.089$; Free Play, $\mathrm{r}=-$ $.249, p=.069 ;$ Movie $, \mathrm{r}=-.231, p=.093$, respectively. Additionally, seatwork completion in the Free Play, placebo condition was significantly correlated with RTV in both SR and NR blocks in the medication condition, $r=-.304$ and $r=-.312$, respectively. Correlations were moderate in the expected direction, i.e., greater RTV was associated with lower seatwork completion. 


\section{CHAPTER IV}

\section{DISCUSSION}

The current study is the first to experimentally manipulate and evaluate mind wandering (MW) among children with ADHD. Aims were to determine if children with ADHD are uniquely susceptible to and affected by MW compared to typically developing peers and whether increased MW results in impaired academic productivity. Children with and without ADHD completed a sustained attention task that presented selfreferential (SR) and non-self-referential (NR) photographs, and mean reaction time (RT) and variability in response time (RTV) served as primary cognitive outcome measures. Additionally, the ADHD group participated in a classroom study aimed at increasing MW to the detriment of classwork productivity. Results indicate that 1) children with ADHD are uniquely susceptible to MW as evidenced by the significant increase in RTV following SR stimuli among children with ADHD and no significant effect of SR stimuli on RTV among children without ADHD, 2) MW manipulations in an analogue classroom setting resulted in decreased classwork productivity, and 3) stimulant medication decreased RTV and increased academic productivity but did not reduce the effect of MW manipulations on the computer task or in the classroom.

Despite decades of research, the underlying mechanisms of impaired attention among children with ADHD are not clear. Overlap among emerging research in attentional dysfunction, MW correlates and effects, and systems neuroscience implicates heightened internal thought distraction or MW as an explanatory mechanism of impaired sustained attention among children with ADHD. Importantly, research has largely relied on self-reported thought content during attentional lapses to quantify MW. This method 
would be invalid among children with ADHD given that they are documented poor selfreporters (Hoza et al., 2004; Owens, Goldfine, Evangelista, Hoza, \& Kaiser, 2007), and it is inappropriate to expect them to accurately report their own internal state or thoughts. To overcome this barrier, the current study is the first to evaluate $\mathrm{mW}$ among children with ADHD by experimentally manipulating MW on a laboratory-based task.

Simultaneously, we developed an analogue classroom study to manipulate MW in a classroom setting. Specifically, we introduced self-referential distractors during a cognitive task and in the classroom setting to experimentally increase self-referential thought distraction or MW.

Mind Wandering on the Sustained Attention to Response Task

Consistent with hypotheses and previous research, ADHD status did not predict longer average RT. Interestingly, SR stimuli did predict significantly longer average RT across groups. Children responded to non-target trials about $20 \mathrm{~ms}$ slower following SR stimuli presentation. This validates the use of SR stimuli to impact sustained attention, and this increased average reaction time strongly suggests internal distraction interference.

The primary outcome of interest, though, was RTV as children with ADHD have consistently been shown to have greater variability in attentional performance than typically developing children (Kofler et al., 2013). Results confirm hypotheses indicating a main effect of SR stimuli and ADHD status on RTV. Further, exploring the marginally significant interaction between SR stimuli and ADHD group indicated that RTV was heightened after SR stimuli only among the children with ADHD, and SR stimuli did not lead to increased RTV among children without ADHD. In other words, children with 
ADHD are uniquely susceptible to MW or internal thought distraction after selfreferential stimulus presentation. Results confirm hypotheses and support the underlying theory that internal thought distraction, potentially related to DMN intrusion (see Querne et al., 2014), underlies the attention problems characteristic of childhood ADHD.

Further, moderate correlations between performance on this MW SART and classroom performance were found among children with ADHD. This indicates that the MW SART may be particularly effective at eliciting and approximating the behavior and performance of children with ADHD in naturalistic settings such as the classroom, providing further support that MW is related to attentional problems and distractibility in laboratory and naturalistic settings among children with ADHD.

\section{Mind Wandering in the Classroom Study}

In the classroom, MW was manipulated by introducing a salient stimulus prior to and after seatwork completion in order to increase the probability that children would be thinking about something other than the assigned classwork. To this end, children were able to play with tablets and other toys or watch an engaging children's movie before and after seatwork, and their productivity on Free Play and Movie days was compared to their productivity on days in which ostensibly non-engaging newscasts were played. Results indicate a significant interaction between MW condition and MPH. When receiving placebo, children with ADHD completed less work in the Free Play condition compared to both the control and Movie conditions. When receiving medication, however, children with ADHD completed less work in both MW conditions (Free Play and Movie) compared to the control condition. 
Altogether, we found support for reduced seatwork productivity on MW days such that children completed about 3 fewer problems during the 30 minute activity. Three problems may not appear to be a clinically substantial amount of work to leave incomplete. However, the current study is aiming to increase mind wandering in a group of children that are likely already experiencing impairing mind wandering prior to the introduction of any manipulation. As such, findings indicate that children with ADHD are susceptible to MW and that MW negatively impacts their academic performance. Free Play may have more effectively increased MW when children were receiving placebo because children were able to choose what they played with. Thus, the activity was by definition more self-determined and therefore more likely to produce self-referential thought distraction that watching a movie.

\section{Medication Effects Across Settings}

The effects of evidence-based treatments on MW among children with ADHD are also critical to asses given the majority of children with ADHD in the United States currently receive stimulant medication (61-69\%; Danielson et al., 2018; Visser et al., 2014). Results from the current study indicate that stimulant medication improves attentional performance and classroom productivity, confirming hypotheses and replicating decades of research supporting stimulant efficacy (Pliszka, 2007; Swanson et al., 1993). However, stimulants did not specifically ameliorate MW in the current study. When children with ADHD received stimulant medication, they remained susceptible to increased MW in the classroom and the cognitive task.

In fact, children with ADHD were more susceptible to MW in the classroom when receiving stimulant medication as evidenced by the significantly reduced 
productivity in both the Free Play and Movie MW conditions compared to the control condition. This could be due to a ceiling effect in the placebo condition such that unmedicated children with ADHD experience highly frequent instances of MW that were not increased further by watching a movie before and after class but may have increased further when toys of their choice were available before and after seatwork. Alternatively, when children with ADHD received stimulant medication, the Movie and Free Play MW conditions both led to increased MW measured by impaired performance. Despite the persistent effect of the MW conditions on performance, MPH led to a consistent increase in productivity. Children with ADHD completed about 20 more problems when they received MPH compared to placebo in the 30 minute period across MW conditions. These results are consistent with decades of research indicating that MPH improves seatwork productivity among children with ADHD Carlson et al., 1992; Pelham et al., 1993; Pelham et al., 1995; Pelham et al., 2001). Importantly, the effects of behavioral modification or combined treatment on MW among children with ADHD has not been evaluated.

\section{Limitations and Future Directions}

The current study is novel in its methods and design, and as such, also bears limitations. The task and classroom manipulations designed to increase MW may not be specifically targeting the cognitive phenomenon of MW but rather another aspect of offtask behavior. However, three different manipulations designed to increase MW based on the intersection between the extant MW and neuroscientific literatures were used, and each manipulation led to impaired attentional performance and productivity. The success

of these specific, controlled, and thoughtful manipulations in increasing off-task behavior 
and RTV is clear evidence that children with ADHD are uniquely and highly susceptible to internal distraction, i.e., MW. As such, the cognitive task manipulation developed for this study should be used by other researchers aiming to evaluate MW among children. The current study is also limited in that a larger battery of cognitive tasks was not completed by study participants. Future research should utilize the MW SART developed herein in conjunction with other cognitive tasks to further explicate the convergent and discriminate validity of the MW SART.

The classroom manipulations are a substantial first step in establishing whether MW affects classroom performance among children with ADHD. Future research may benefit from ensuring the distractors are sufficiently self-referential as the SR nature of stimuli may explain the stronger results found for the Free Play condition compared to the Movie condition in the classroom. Specifically, children were able to choose what they played with and were interacting more with the stimuli before and after seatwork in the Free Play condition compared to passively watching a movie. Further, the amount of time between stimuli in the classroom study, 30 minutes, likely partially explains the comparatively weaker findings in the classroom setting compared to the controlled, laboratory manipulations of MW. More work is needed to attempt to quantify MW as it occurs, i.e., without experimentally increasing MW. However, based on the literature, we discourage investigators from simply asking a child with ADHD if he or she is off-task or what he or she is thinking.

\section{Conclusions}

The current study developed and implemented novel methods to provide groundbreaking support for the hypothesis that children with ADHD experience 
heightened MW and that increased MW negatively impacts classroom productivity. Results indicate that MW can be increased via manipulations to cognitive task design and classroom procedures. This foundational work will allow researchers to continue exploring the phenomenon of MW among children, an area of study that to this point has been markedly limited. Further, results indicate that the attentional performance of children with ADHD is negatively affected by MW, and that children with ADHD are uniquely susceptible to SR internal thought distraction and MW in the controlled laboratory setting. It is clear that MW may be an underlying dysfunction among individuals with ADHD, and further explication of the ways in which MW negatively affects individuals with ADHD may lead to exciting advances in treatment development and implementation. 


\section{LIST OF REFERENCES}

Achenbach, T. M., \& Rescorla, L. A. (2001). Manual for the ASEBA School-Age Forms \& Profiles. Burlington, VT: University of Vermont, Research Center for Children, Youth, \& Families.

American Psychiatric Association. (2013). Diagnostic and statistical manual of mental disorders (5th ed.). Washington, DC: Author.

Andrews-Hanna, J. R., Reidler, J. S., Sepulcre, J., Poulin, R., \& Buckner, R. L. (2010). Functional-anatomic fractionation of the brain's default network. Neuron, 65(4), 550562. http://doi.org/10.1016/j.neuron.2010.02.005

Barkley, R. A., Murphy, K. R., \& Fischer, M. (2010). ADHD in Adults: What the Science Says. New York, NY: Guilford Press.

Buckner, R. L., Andrews-Hanna, J. R., \& Schacter, D. L. (2008). The brain's default network: anatomy, function, and relevance to disease. Annals of the New York Academy of Sciences, 1124(1), 1-38. http://doi.org/10.1196/annals.1440.011

Carlson, C. L., Pelham, W. E., Milich, R., \& Dixon, J. (1992). Single and combined effects of methylphenidate and behavior therapy on the classroom performance of children with attention-deficit hyperactivity disorder. Journal of Abnormal Child Psychology, 20(2), 213-232.

Centers for Disease Control and Prevention. (2011). Increasing prevalence of parentreported attention-deficit/hyperactivity disorder among children. United States, 2003 and 2007. Morbidity and Mortality Weekly Report, 59, 1439-1443.

Cheyne, J. A., Solman, G. J. F., Carriere, J. S. A., \& Smilek, D. (2009). Anatomy of an error: A bidirectional state model of task engagement/disengagement and attentionrelated errors. Cognition, 111(1), 98-113. http://doi.org/10.1016/j.cognition.2008.12.009

Christoff, K., Gordon, A. M., Smallwood, J., Smith, R., \& Schooler, J. W. (2009). Experience sampling during fMRI reveals default network and executive system contributions to mind wandering. Proceedings of the National Academy of Sciences of the United States of America, 106(21), 8719-24. http://doi.org/10.1073/pnas.0900234106

Cortese, S., Kelly, C., Chabernaud, C., Proal, E., Di Martino, A., Milham, M. P., ... Castellanos, F. X. (2012). Toward systems neuroscience of ADHD: A meta-analysis of 55 fMRI studies. The American Journal of Psychiatry, 169(10), 1038-1055. http://doi.org/10.1176/appi.ajp.2012.11101521

Danielson, M. L., Bitsko, R. H., Ghandour, R. M., Holbrook, J. R., Kogan, M. D., \& Blumberg, S. J. (2018). Prevalence of parent-reported ADHD diagnosis and associated 
treatment among US children and adolescents, 2016. Journal of Clinical Child \& Adolescent Psychology, 47(2), 199-212.

Epstein, J. N., Langberg, J. M., Rosen, P. J., Graham, A., Narad, M. E., Antonini, T. N., ... Simon, J. O. (2011). Evidence for higher reaction time variability for children with ADHD on a range of cognitive tasks including reward and event rate manipulations. Neuropsychology, 25(4), 427-441. http://doi.org/10.1037/a0022155.

Fabiano, G. A., Pelham, W. E., Gnagy, E. M., Burrows-Maclean, L., Coles, E. K., Chacko, A., ... Robb, J. A. (2007). The single and combined effects of multiple intensities of behavior modification and methylphenidate for children with Attention Deficit Hyperactivity Disorder in a classroom setting. School Psychology Review, 36(2), 195-216.

Franklin, M. S., Mrazek, M. D., Anderson, C. L., Johnston, C., Smallwood, J., Kingstone, A., \& Schooler, J. W. (2014). Tracking distraction: The relationship between mindwandering, meta-awareness, and ADHD symptomatology. Journal of Attention Disorders, 21(6), 475-486.. http://doi.org/10.1177/1087054714543494

Greenhill, L. L., Swanson, J. M., Vitiello, B., Davies, M., Clevenger, W., Wu, M., ... \& Elliott, G. R. (2001). Impairment and deportment responses to different methylphenidate doses in children with ADHD: The MTA titration trial. Journal of the American Academy of Child \& Adolescent Psychiatry, 40(2), 180-187.

Hart, K. C., Massetti, G. M., Fabiano, G. A., Pariseau, M. E., \& Pelham Jr, W. E. (2011). Impact of group size on classroom on-task behavior and work productivity in children with ADHD. Journal of Emotional and Behavioral Disorders, 19(1), 55-64.

Hoza, B., Gerdes, A. C., Hinshaw, S. P., Arnold, L. E., Pelham, W. E., Molina, B. S. G., ... Wigal, T. (2004). Self-perceptions of competence in children with ADHD and comparison children. Journal of Consulting and Clinical Psychology, 72(3), 382-91. http://doi.org/10.1037/0022-006X.72.3.382

Huang-Pollock, C. L., Nigg, J. T., \& Carr, T. H. (2005). Deficient attention is hard to find: Applying the perceptual load model of selective attention to attention deficit hyperactivity disorder subtypes. Journal of Child Psychology and Psychiatry and Allied Disciplines, 46(11), 1211-1218. http://doi.org/10.1111/j.1469-7610.2005.00410.x

Kofler, M. J., Rapport, M. D., Sarver, D. E., Raiker, J. S., Orban, S. A., Friedman, L. M., \& Kolomeyer, E. G. (2013). Reaction time variability in ADHD: A meta-analytic review of 319 studies. Clinical Psychology Review, 33(6), 795-811.

http://doi.org/10.1016/j.cpr.2013.06.001

Massetti, G. M., Pelham, W. E., Chacko, A., Walker, K. S., Arnold, F., Coles, E. K., \& Burrows-MacLean, L. (2003, November). Situational variability of ADHD, ODD, and 
CD: Psychometric properties of the DBD interview and rating scale. In Poster presented at the Association for Advancement of Behavior Therapy Conference, Boston.

Merrill, B. M., Morrow, A. S., Altszuler, A. R., Macphee, F. L., Coxe, S., Gnagy, E. M., Greiner, A. R., Molina, B. S. G., \& Pelham, W. E. (2019). Functional outcomes of young adults with childhood ADHD: A latent profile analysis. Journal of Abnormal Psychology, $1-14$.

Milich, R., \& Pelham, W. E. (1986). Effects of sugar ingestion on the classroom and playgroup behavior of attention deficit disordered boys. Journal of Consulting and Clinical Psychology, 54(5), 714.

Mowlem, F. D., Skirrow, C., Reid, P., Maltezos, S., Nijjar, S. K., Merwood, A., ... Asherson, P. (2016). Validation of the mind excessively wandering scale and the relationship of mind wandering to impairment in adult ADHD. Journal of Attention Disorders, 23(6), 624-634. http://doi.org/10.1177/1087054716651927

Mrazek, M. D., Smallwood, J., \& Schooler, J. W. (2012). Mindfulness and mindwandering: Finding convergence through opposing constructs. Emotion, 12(3), 442-448. http://doi.org/10.1037/a0026678

Nigg, J. T., \& Barkley, R. (2014). Attention-Deficit/Hyperactivity Disorder. In E. J. Mash \& R. Barkley (Eds.), Child Psychopathology (3rd ed.). New York, NY: Guilford Press.

Owens, J. S., Goldfine, M. E., Evangelista, N. M., Hoza, B., \& Kaiser, N. M. (2007). A critical review of self-perceptions and the positive illusory bias in children with ADHD. Clinical Child and Family Psychology Review, 10(4), 335-351.

http://doi.org/10.1007/s10567-007-0027-3

Pariseau, M. E., Fabiano, G. A., Massetti, G. M., Hart, K. C., \& Pelham Jr, W. E. (2010). Extended time on academic assignments: Does increased time lead to improved performance for children with attention-deficit/hyperactivity disorder? School Psychology Quarterly, 25(4), 236.

Pelham, W. E., Carlson, C., Sams, S. E., Vallano, G., Dixon, M. J., \& Hoza, B. (1993). Separate and combined effects of methylphenidate and behavior modification on boys with Attention Deficit-Hyperactivity Disorder in the classroom. Journal of Consulting and Clinical Psychology, 61(3), 506.

Pelham, W. E., Fabiano, G. A., \& Massetti, G. M. (2005). Evidence-based assessment of Attention Deficit Hyperactivity Disorder in children and adolescents. Journal of Clinical Child and Adolescent Psychology, 34(3), 449-76.

http://doi.org/10.1207/s15374424jccp3403_5 
Pelham, W. E., Foster, E. M., \& Robb, J. A. (2007). The economic impact of AttentionDeficit/Hyperactivity Disorder in children and adolescents. Journal of Pediatric Psychology, 32(6), 711-27. http://doi.org/10.1093/jpepsy/jsm022

Pelham, W. E., Gnagy, E. M., Burrows-Maclean, L., Williams, A., Fabiano, G. A., Morrisey, S. M., ... \& Lock, T. M. (2001). Once-a-day Concerta methylphenidate versus three-times-daily methylphenidate in laboratory and natural settings. Pediatrics, 107(6), e105-e105.

Pelham, W. E., Gnagy, E. M., Greiner, A. R., Waschbusch, D. A., Fabiano, G., \& Burrows-Maclean, L. (2010). Summer Treatment Programs for AttentionDeficit/Hyperactivity Disorder. In J. R. Weisz \& A. E. Kazdin (Eds.), Evidence-Based Psychotherapies for Children and Adolescents (2nd ed., pp. 277-292). New York, NY: Guilford Press.

Pelham Jr, W. E., Swanson, J. M., Furman, M. B., \& Schwindt, H. (1995). Pemoline effects on children with ADHD: a time-response by dose-response analysis on classroom measures. Journal of the American Academy of Child \& Adolescent Psychiatry, 34(11), 1504-1513.

Pelham, W. E., Waschbusch, D. A., Hoza, B., Gnagy, E. M., Greiner, A. R., Sams, S. E., ... Carter, R. L. (2011). Music and video as distractors for boys with ADHD in the classroom: Comparison with controls, individual differences, and medication effects. Journal of Abnormal Child Psychology, 39(8), 1085-1098.

http://doi.org/10.1007/s10802-011-9529-z

Pliszka, S. R. (2007). Pharmacologic treatment of attention-deficit/hyperactivity disorder: efficacy, safety and mechanisms of action. Neuropsychology Review, 17, 61-72. doi:10.1007/s11065-006-9017-3

Querne, L., Fall, S., Le Moing, A.-G., Bourel-Ponchel, E., Delignières, A., Simonnot, A., ... Berquin, P. (2014). Effects of methylphenidate on default-mode network/task-positive network synchronization in children With ADHD. Journal of Attention Disorders, 21(14), 1208-1220. http://doi.org/10.1177/1087054713517542

Robb, J. A., Sibley, M. H., Pelham, W. E., Michael Foster, E., Molina, B. S. G., Gnagy, E. M., \& Kuriyan, A. B. (2011). The estimated annual cost of ADHD to the US education system. School Mental Health, 3(3), 169-177. http://doi.org/10.1007/s12310-011-9057-6

Seli, P., Carriere, J. S. A, Thomson, D. R., Cheyne, J. A., Martens, K. A.E., \& Smilek, D. (2014). Restless mind, restless body. Journal of Experimental Psychology: Learning, Memory, and Cognition, 40(3), 660-668. http://doi.org/10.1037/a0035260

Seli, P., Smallwood, J., Cheyne, J. A., \& Smilek, D. (2015). On the relation of mind wandering and ADHD symptomatology. Psychonomic Bulletin \& Review, 22(3), 629636. http://doi.org/10.3758/s13423-014-0793-0 
Smallwood, J., Beach, E., Schooler, J. W., \& Handy, T. C. (2008). Going AWOL in the brain: Mind wandering reduces cortical analysis of external events. Journal of Cognitive Neuroscience, 20(3), 458-69. http://doi.org/10.1162/jocn.2008.20037

Smallwood, J., Fishman, D. J., \& Schooler, J. W. (2007). Counting the cost of an absent mind: Mind wandering as an underrecognized influence on educational performance. Psychonomic Bulletin \& Review, 14(2), 230-236. http://doi.org/10.3758/BF03194057

Swanson, J. M., McBurnett, K., Wigal, T., Pfiffner, L. J., Lerner, M. A., Williams, L., ... \& Clevenger, W. (1993). Effect of stimulant medication on children with attention deficit disorder: A "review of reviews". Exceptional children, 60(2), 154-162.

Tamm, L., Narad, M. E., Antonini, T. N., O’Brien, K. M., Hawk, L. W., \& Epstein, J. N. (2012). Reaction time variability in ADHD: A review. Neurotherapeutics, 9(3), 500-508. http://doi.org/10.1007/s13311-012-0138-5

Van den Driessche, C., Bastian, M., Peyre, H., Stordeur, C., Acquaviva, É., Bahadori, S., ... \& Sackur, J. (2017). Attentional lapses in Attention-Deficit/Hyperactivity Disorder: Blank rather than wandering thoughts. Psychological Science, 28(10), 1375-1386.

Visser, S. N., Danielson, M. L., Bitsko, R. H., Holbrook, J. R., Kogan, M. D., Ghandour, R. M., ... \& Blumberg, S. J. (2014). Trends in the parent-report of health care providerdiagnosed and medicated attention-deficit/hyperactivity disorder: United States, 20032011. Journal of the American Academy of Child \& Adolescent Psychiatry, 53(1), 34-46.

Wechsler, D. (2009). Wechsler Individual Achievement Test (3rd Ed.). San Antonio, Texas: Pearson.

Wechsler, D. (2011). Wechsler Abbreviated Scale of Intelligence (2nd Ed.). San Antonio, Texas: Pearson.

Weissman, D. H., Roberts, K. C., Visscher, K. M., \& Woldorff, M. G. (2006). The neural bases of momentary lapses in attention. Nature Neuroscience, 9(7), 971-8. http://doi.org/10.1038/nn1727 
Table 1. Participant Demographics

\begin{tabular}{|c|c|c|}
\hline & ADHD, $\mathrm{N}=59$ & Control, $\mathrm{N}=55$ \\
\hline Age & $8.7(1.44)$ & $9.26(1.58)$ \\
\hline Male Gender, $\mathrm{n}(\%)$ & $47(79.7 \%)$ & $45(80.4 \%)$ \\
\hline Hispanic Ethnicity, n(\%) & $51(87.9 \%)$ & $47(83.9 \%)$ \\
\hline \multicolumn{3}{|l|}{ Race, $n(\%)$} \\
\hline White & $50(84.7 \%)$ & $48(85.7 \%)$ \\
\hline Black & $7(11.9 \%)$ & $5(8.9 \%)$ \\
\hline Asian & $2(3.4 \%)$ & $3(5.4 \%)$ \\
\hline Parent Marital Status, n(\%) & $* *$ & \\
\hline Single, not living with partner & $20(34.5 \%)$ & $15(27.3 \%)$ \\
\hline Married or living with partner & $38(65.5 \%)$ & $40(72.7 \%)$ \\
\hline Highest Parent Education, n(\%) & ** & \\
\hline Some Highschool & $1(1.7 \%)$ & $0(0 \%)$ \\
\hline Highschool Diploma & $11(18.6 \%)$ & $1(1.8 \%)$ \\
\hline Some College & $12(20.3 \%)$ & $8(14.3 \%)$ \\
\hline Associates Degree or Technical School & $8(13.6 \%)$ & $9(16.1 \%)$ \\
\hline Bachelor's Degree & $17(28.8 \%)$ & $18(32.1 \%)$ \\
\hline Graduate Training & $10(16.9 \%)$ & $20(35.7 \%)$ \\
\hline Grade & $2.8(1.49)$ & $3.2(1.60)$ \\
\hline FSIQ & $96.47(12.47)^{* * *}$ & $106.91(11.77)$ \\
\hline \multicolumn{3}{|l|}{ Achievement Scores } \\
\hline Word Reading & $98.75(16.18)^{* *}$ & $108.13(13.81)$ \\
\hline Numerical Operations & $102.47(11.89)^{* *}$ & $110.75(13.53)$ \\
\hline Spelling & $98.11(16.46)^{* * *}$ & $111.24(16.17)$ \\
\hline \multicolumn{3}{|l|}{ CBCL T-Scores } \\
\hline Anxious/Depressed & $60.45(9.03)^{* * *}$ & $54.29(6.15)$ \\
\hline Withdrawn/Depressed & $58.33(8.60)^{* *}$ & $53.80(5.39)$ \\
\hline Attention Problems & $70.91(9.55)^{* * *}$ & $52.51(3.65)$ \\
\hline Internalizing Problems & $59.66(10.01)^{* * *}$ & $48.41(9.96)$ \\
\hline Externalizing Problems & $61.72(9.06)^{* * *}$ & $44.96(9.08)$ \\
\hline
\end{tabular}


Table 2. Sustained Attention to Response Task (SART) Performance

\begin{tabular}{ccccccc}
\hline & \multicolumn{2}{c}{ Control } & \multicolumn{2}{c}{ ADHD, placebo } & \multicolumn{2}{c}{ ADHD, medication } \\
\cline { 2 - 7 } & NR Block & SR Block & NR Block & SR Block & NR Block & SR Block \\
\cline { 2 - 7 } Average RT & $489.41(1.02)$ & $506.89(1.02)^{1}$ & $501.20(1.02)$ & $523.43(1.02)^{1}$ & $508.82(1.02)$ & $527.47(1.02)^{1}$ \\
RTV & $71.43(1.04)^{2}$ & $72.41(1.04)^{2}$ & $88.33(1.04)$ & $96.67(1.04)^{1}$ & $81.10(1.04)^{2}$ & $86.47(1.04)^{2}$
\end{tabular}

$\overline{\mathrm{RT}}=$ reaction time, $\mathrm{RTV}=$ reaction time variability measured by reaction time standard deviation, $\mathrm{SE}=$ standard error of measurement. ${ }^{1}$ Significant effect of SR stimuli at $\mathrm{p}<.05,{ }^{2}$ Significantly different than ADHD, placebo at $\mathrm{p}<.05$. Results indicate that control participants had longer average RT in the SR block than the NR block and that RTV was lower in the control group than in the ADHD placebo group. Among children with ADHD, average RT and RTV were higher in the SR block than the NR block when receiving placebo, and average RT, but not RTV, is higher in the SR block when receiving stimulant medication. RTV is significantly lower among children with ADHD when they are receiving medication compared to when they are receiving placebo. 
Table 3. Seatwork Completion Among Children with ADHD.

\begin{tabular}{lccc}
\hline & \multicolumn{3}{c}{ MW Condition } \\
\cline { 2 - 4 } & Control & Free Play & Movie \\
\cline { 2 - 4 } Placebo & $75.95(5.07)$ & $72.74(4.86)^{1}$ & $76.16(5.09)$ \\
Medication & $100.26(6.68)^{2}$ & $97.51(6.50)^{1,2}$ & $97.74(6.52)^{1,2}$
\end{tabular}

${ }^{1}$ Significant effect of MW condition (Free Play or Movie) compared to Control condition at $\mathrm{p}<.05,{ }^{2}$ Significant effect of medication at $\mathrm{p}<.05$. 
Table 4. Correlations Between Reaction Time Variability and Seatwork Completion.

\begin{tabular}{|c|c|c|c|c|c|c|c|c|c|c|}
\hline & & & \multicolumn{4}{|c|}{ Average RT } & \multicolumn{4}{|c|}{ RTV } \\
\hline & & & \multicolumn{2}{|c|}{ Placebo } & \multicolumn{2}{|c|}{$\mathrm{MPH}$} & \multicolumn{2}{|c|}{ Placebo } & \multicolumn{2}{|c|}{$\mathrm{MPH}$} \\
\hline & & & NR & SR Block & NR & SR Block & NR & SR Block & NR & SR Block \\
\hline & & & Block & & Block & & Block & & Block & \\
\hline \multirow{6}{*}{ 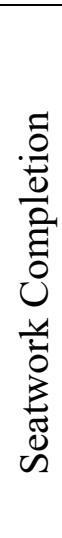 } & Placebo & MW Control & .081 & .086 & .033 & .015 & $-.241^{\dagger}$ & -.184 & $-.227^{\dagger}$ & $-.239^{\dagger}$ \\
\hline & & Free Play & .049 & .061 & -.086 & -.085 & $-.230^{\dagger}$ & -.147 & $-.312^{*}$ & $-.304^{*}$ \\
\hline & & Movie & .129 & .104 & -.017 & -.004 & -.058 & -.048 & $-.232^{\dagger}$ & -.194 \\
\hline & $\mathrm{MPH}$ & MW Control & .163 & .047 & -.068 & -.033 & .081 & -.021 & $-.233^{\dagger}$ & -.207 \\
\hline & & Free Play & .118 & -.007 & -.079 & -.034 & .090 & -.021 & $-.249^{\dagger}$ & -.193 \\
\hline & & Movie & .115 & -.014 & -.026 & -.019 & .080 & -.056 & -.231 & -.166 \\
\hline
\end{tabular}

$\mathrm{MW}=$ Mind wandering, MPH= Methylphenidate, SR block = epoch of three trials during the MW SART following a selfreferential stimulus, NR block $=$ epoch of three trials during the MW SART following a non-self-referential stimulus. ${ }^{\dagger} p<.10,{ }^{*}$ $p<.05$. 
Figure 1. Effect of Mind Wandering Condition and ADHD Status on Reaction Time Variability.

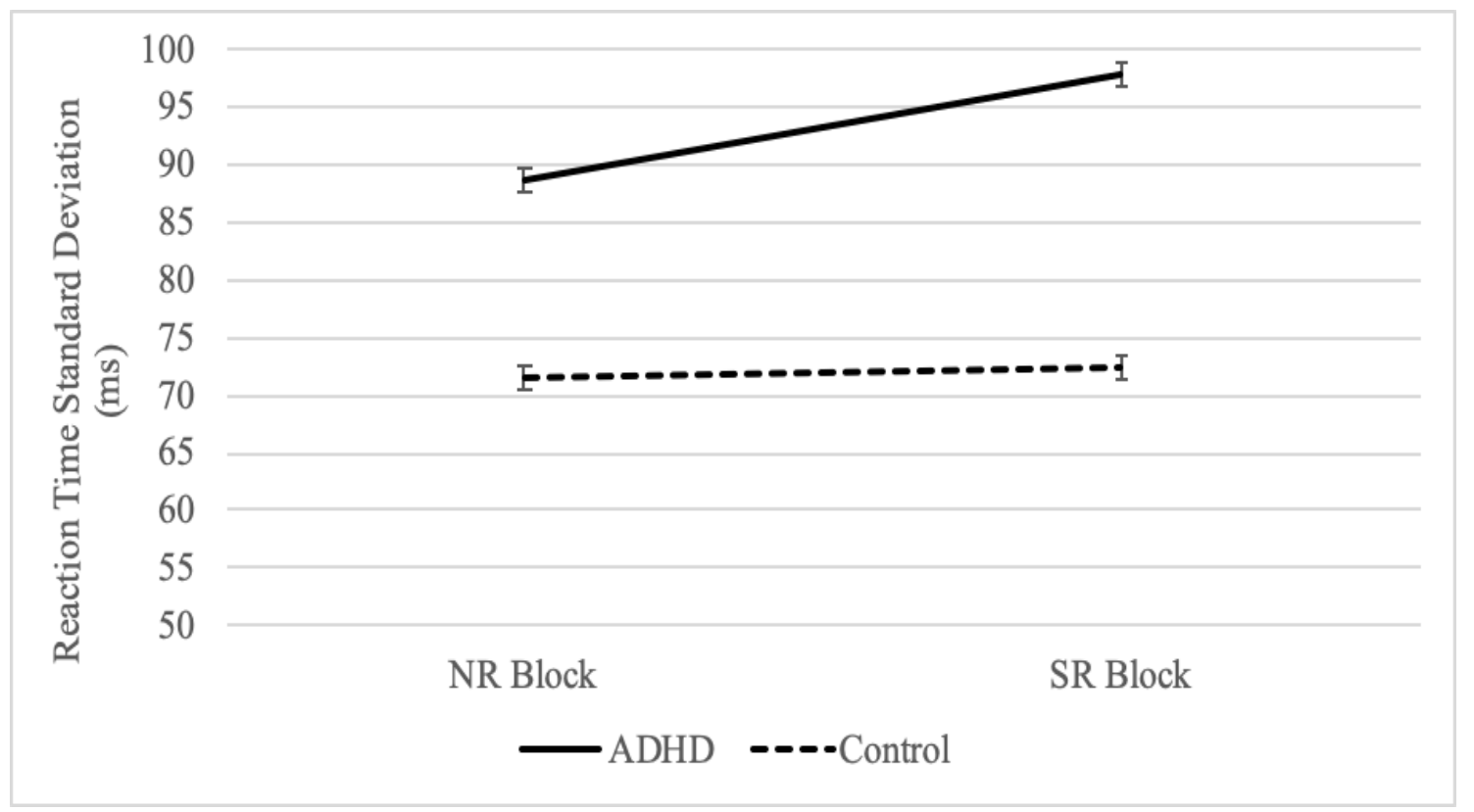

$\mathrm{NR}=$ non-self-referential, $\mathrm{SR}=$ self-referential. The interaction between block type (NR vs. SR block) and ADHD status in the sustained attention task was marginally significant. In the control group, block type did not impact reaction time variability (measured by reaction time standard deviation) whereas, in the ADHD group, there was a significant increase in reaction time variability in the SR block compared to the NR block. 
VITA

\section{BRITTANY M. MERRILL}

2009-2012

B.S., Psychology

DePaul University

Chicago, Illinois

2012-2013

Project Coordinator

University of Illinois at Chicago

Chicago, Illinois

2013-2016

M.S., Clinical Science in Child and Adolescent Psychology Florida International University

Miami, Florida

2013-2020

Doctoral Candidate, Clinical Science in Child and

Adolescent Psychology

Florida International University

Miami, Florida

\section{SELECTED PUBLICATIONS AND PRESENTATIONS}

Schatz, N. K., Aloe, A. M., Fabiano, G. A., Pelham, W. E., Smyth, A., Merrill, B. M., ... \& Hong, N. (under review). Systematic review and network meta-analysis: Relative efficacy of stand-alone and complex psychosocial interventions for children with ADHD.

Pelham, W. E. III, Altszuler, A. R., Merrill, B. M., Raiker, J. S., Macphee, F. L., Ramos, M., Gnagy, E. M., Coles, E. K., Connor, C. M., Lonigan, C. J., Burger, L., Morrow, A. S., Zhao, X., Waxmonsky, J. G., \& Pelham, W. E. Jr. (under review). Effect of stimulant medication on learning of authentic academic curricula in children with ADHD.

Schatz, N. K., Aloe, A. M., Fabiano, G. A., Pelham, W. E., Smyth, A., Zhao, X., Merrill, B. M., ... \& Altszuler, A. R. (2020). Psychosocial interventions for Attention-Deficit /Hyperactivity Disorder: Systematic review with evidence and gap maps. Journal of Developmental \& Behavioral Pediatrics. 41, S77-S87.

Babinski, D. E., Robb Mazzant, J., Merrill, B. M., Waschbusch, D. A., Sibley, M. H., Gnagy, E. M., Molina, B. S. G., \& Pelham, W. E. (2019). Lifetime caregiver strain among mothers of adolescents and young adults with Attention-Deficit/Hyperactivity Disorder. Journal of Family Psychology.

Macphee, F. L., Merrill, B. M., Altszuler, A. R., Morrow, A. S., Ramos, M. C., Gnagy, E. M., Greiner, A. R., Coxe S., Raiker, J. S., Coles, E. \& Pelham, W. E. (2019). The effect 
of weighted vests and stability balls in combination with and without psychostimulant medication on classroom outcomes in children with ADHD. School Psychology Review, 48(3), 276-289.

Zhao, X., Page, T., Altszuler, A. R., Pelham, W. E. III, Kipp, H., Gnagy, E. M., Coxe, S., Schatz, N. K., Merrill, B. M., Macphee, F. L., \& Pelham, W. E. (2019). Family burden of raising a child with ADHD. Journal of Abnormal Child Psychology, 47(8), 1327-1338.

Merrill, B. M., Molina, B. S. G., Coxe, S., Gnagy, E. M., Altszuler, A. R., Macphee, F. L., Morrow, A. S. Trucco, E. M., \& Pelham, W. E. (2019). Functional outcomes of young adults with childhood ADHD: A latent profile analysis. Journal of Clinical Child and Adolescent Psychology, 1-14.

Altszuler, A. R., Morrow, A. S., Merrill, B. M., Bressler, S., Macphee, F. L., Gnagy, E. M., Greiner, A. R., Coxe, S., Raiker, J. S., Coles, E. K., \& Pelham, W. E. (2017). The effect of stimulant medication and training on the sports competence of children with ADHD. Journal of Clinical Child and Adolescent Psychology, 48(sup1):S155-S167.

Macphee, F. L., Altszuler, A. R., Merrill, B. M., \& Pelham, W. E. (2017). Improving daily life functioning of children with ADHD: Medication, behavioral intervention, or their combination- "Just Say Yes to Drugs?" Redux. The Clinical Psychologist, 70, 5-14.

Merrill, B. M., Morrow, A. S., Altszuler, A. R., Macphee, F. L., Gnagy, E. M., Greiner, A. R., Coles, E., Raiker, J. S., Coxe, S., \& Pelham, W. E. (2017). Improving homework performance among children with ADHD: A randomized clinical trial. Journal of Consulting and Clinical Psychology, 85, 111-122.

Sibley, M. H., Campez, M., Perez, A., Morrow, A. S., Merrill, B. M., Altszuler, A. R, \& Yeguez, C. E. (2016). Parent management of organization, time management, and planning deficits among adolescents with ADHD. Journal of Psychopathology and Behavioral Assessment, 38, 216-228.

Sibley, M. H., Altszuler, A. R., Morrow, A. S., \& Merrill, B. M. (2014). Mapping the academic problem behaviors of adolescents with ADHD. School Psychology Quarterly, $29,422-437$. 